\title{
Should I Quit? Understanding Job Stress and Coping Strategies Among Hospitality Students During on the Job Training Program
}

\author{
Nana Trianasari*, Putu Indah Rahmawati \\ Management Department \\ Universitas Pendidikan Ganesha \\ Bali, Indonesia \\ *nanatrianasari01@gmail.com
}

\begin{abstract}
One of the important components of vocational education curriculum is the "on the job training program" which provides both opportunities and challenges for students in a workplace-based setting. Through this program, hospitality students experience and become part of hotel's daily operations which thus expectedly improves their attitude, skills, and knowledge. At the same time, students encounter challenging situations that may trigger job stress. This study aimed at understanding the types of job-related stress experienced by students during on the job training program and how they cope with their problems. The study was conducted by employing a qualitative approach. Participants were recruited using a purposive sampling technique with the criteria of having completed a minimum of 6 months on the job training program. Data were collected from 23 students Using one-to-one semi structured interview method and were analyzed using constant comparative analyses. Findings of the study suggested that the major job stressor was job characteristics in which the variations of daily tasks were highlighted by respondents. Moreover, it was also found that problem personal such as relationship with other particularly during the adaptation period was considered to be a minor source of job stress. Next, the study revealed that most students adopted the direct action strategy in coping with their problems Only a few students considered the internalizing strategy. These findings provide insights into curriculum development and teaching method that may focus more on the technical aspect of task performance and problem-solving. Moreover, empowerment and flexibility should also be encouraged by the hotel in treating intern students. Thereby, students' readiness to attend the on the job training program can be enhanced. Further discussion of the significance of the study as well as an avenue for future research and study limitations are presented in the paper.
\end{abstract}

Keywords - coping strategy, hospitality, internship, on the job training, vocational education

\section{INTRODUCTION}

The combination of learning and experience is an effective form of teaching [1], particularly in vocational education. A common application of experience-based learning is an internship or on the job training program. Training is defined as providing job-related competencies to solve problems at work [2]. This program is one of the key components of a vocational study [2,3] that provides students with an opportunity to actively engage in their learning [4].

The on the job training program requires at least three parties to coordinate which are school or campus, students, and industry [1]. The three parties are responsible for ensuring the program is successful. As such, it is important for the campus and industry to design good training programs with meaningful tasks and empowerment to perform the tasks more creatively [5]. On the other hand, students are required to attend and actively participate in the whole program. Within hospitality education, the on-the-job training program involves firms such as hotel, restaurant, and other hospitality businesses. In many cases, students could take the program from 3-6 months. One of the purposes of this program is to allow students to experience and to become part of the real operations of hotel or restaurant which potentially include interactions either with hotel guests or other employees. As such, students are required to have the ability to adapt in terms of performing certain tasks or jobs that may differ from what they learn on campus and, in relating to others.

Previous studies have emphasized that the hospitality industry is a heavy people business [6,7] which requires good skill to relate to others. Moreover, it is a complex and demanding industry, labor-intensive, anti-social working hours, intensive contacts with customers, and highly emotional labor characteristics with changing environment [7] that potentially lead to heavy workload, pressure [6,8-10] and, burnout [11-13] Such stressful characteristic has triggered interests in studies on coping strategy [7,13-15].

As part of the daily business operations, such a demanding environment seems to be inevitable for students. In other words, students also have the opportunity to experience the operational situation and most likely tensions while on-the-job training either it relates to tasks or interpersonal. However, 
most of the students may not necessarily be ready to overcome such hardships as it may not be specifically taught on campus. Little attention has been given especially by the hospitality school or campus to address this particular issue. The hospitality curricula that focuses more on the professional skill development is considerably lacking subjects about personal development such as how to cope with stress or difficult situation during on the job training.

While on-the-job training has been considered a critical component of hospitality education, previous research has paid little attention to the importance of understanding students' perspectives toward their on-the-job training experiences. Research into issues associated with an internship or on-the-job training program from students' point of view is lacking. In particular, the study that focuses on how students cope with difficulties during on-the-job training is therefore crucial. Much of research on coping strategy has largely looked into the practices of employees [7,11,12,15,16] customers [17], and managers [14]. Few studies have investigated the coping strategy as it relates to student interns [18]. This study aimed at understanding how hospitality students cope with situations during undertaking on the job training program. The specific research objectives are 1) to explore student's problems that may lead to job stress and, 2) to identify student's coping strategies. The results of this study can contribute to curricula development and teaching method, particularly within hospitality education.

\section{LITERATURE REVIEW}

\section{A. On the Job Training (Internship) Program}

The dynamic nature of external factors such as industry trends, technological advancement, and market development have affected the way universities approach their operations. This seemingly continuously changing environment has forced universities to adapt a more vocational approach to their curricula [17,19]. As discussed in the previous section, the internship program is a vital part of vocational education in which students are exposed to an engage-learning method. Through this program, students directly involve in the day-today business operations through which they learn and practice. Students' industrial experience has become compulsory to complement traditional classroom learning. Indeed, Le Maistre state that most students encounter difficulties when directly enter the workplace and pursue their professional careers after classroom activities [20]. As such, internship programs act as a bridge or transition phase and offer an opportunity to overcome any substantial gaps between college-learned theory and practical reality $[21,22]$. This program plays an important role in students' transition from college to the work environment [23]. Besides, the program provides students with valuable work-centered knowledge and work-related experience [24].

Practically, several terms are being used to refer to this industrial program such as student work experience, placements, internships, cooperative education, experiential education, or work-integration education, the practice is thought to help students gain hands-on experience, put textbook theories into action, and reflect on their future careers [25]. Prior real work experience is essential to help students gain competence in their field [26]. While it is beneficial for students' growth in terms of skills, knowledge, and attitude, this program may still need to be continuously evaluated. Being an important component of vocational education [3], assessment of internship or on-the-job training program should be crucial particularly in examining student's satisfaction toward the program. Also, how students feel before, during, and after the program still needs further investigation. Students may frequently feel anxiety, insecurity, and uncertainty when entering an internship program [3]. However, in the literature, research focusing on the internship program has not yet been conclusive [3]. In other words, further research on this topic is arguably needed.

\section{B. Coping Strategy}

The term coping strategy is referred to one's actions intended to reduce stress [27]. Such intention includes cognitive and behavioral efforts to enable the person to cope with the demands of the environment [28]. Concerning the cognitive aspect, coping strategy relates to an analysis or evaluation process during which a person produces affirmative rather than negative results as well as adverse effects caused by stressors [29]. On the other side, the behavioral aspect conceptually constitutes an individual's attempt to respond to stressful conditions at work.

In line with the cognitive and behavioral aspects, two types of coping strategies are problem-focus and emotion-focus [30]. The problem-focus coping strategy involves defining a problem and taking constructive and direct approaches, whereas, the emotion-focus includes emotional responses such as avoidance or seeking emotional support. While the two strategies are distinctive, they are not independent [31] Emphasizing more on the cognitive approach, Latack [32] categorized four dimensions of coping strategies. They are direct action, externalizing, internalizing, and avoidance strategies. Direct action is an attempt made by an individual to directly alter the stressful situation. Externalizing is defined as a conscious restriction of expectations for job satisfaction. Using this strategy, an individual shifts his or her criterion of job satisfaction, from intrinsic to extrinsic. This means that the person is more likely to accept the dissatisfactory condition. Next, internalizing is a more optimistic view of the occupational condition in which an individual views unsatisfying job conditions as temporary. Such a person believes that in future situations will be improved. The last strategy is avoidance in which an individual selectively pay more attention to pleasant situations rather than unpleasant ones so that problems recede from awareness.

A more recent study of Sunny et al., [6] has found the importance of coping strategy on burnout. That is, more application of coping strategies leads to a lower level of burnout. Moreover, a direct-action coping strategy was also found to be influential to reduce job stress. The major stress of 
hotel supervisors derived from task characteristics and workload. The nature of hospitality operations that requires a high level of customer encounter potentially causes job stress and burnout $[6,33]$ which then makes coping strategies essential.

\section{RESEARCH METHODOLOGY}

This research was conducted using a qualitative approach. Data were gathered from 23 hospitality students who had finished a minimum of 6 months on the job training program. The participants were 14 males and 9 females with an average age of 21.2 years old. They were recruited from one university and participated voluntarily in this research. In terms of the location of the on-the-job training program, 20 students were in South Bali and 3 students were in North Bali. Furthermore, 11 students worked in Food and Beverage Department, 3 in Food Production, 3 in the Front Office, 1 in Accounting, 1 in Human Resources, and 4 in Housekeeping of mostly between 4 to 5star hotels. Semi-structured one-to-one interview was used to collect data. Self-developed questions were designed to answer the research questions [34]. At the beginning of the interview, participants were asked general questions related to the hotel and department during the on the job training program as well as the length of the program. Next, questions regarding students' backgrounds such as their name, age, gender, and year of study were asked. The main interview was started with a question regarding their comments on the program. Then, participants were asked to tell about their experience in a more detailed fashion. That is about the memorable experience, both satisfactory and dissatisfactory or stressful ones. Participants were asked to explain their feelings and actions concerning those experiences.

Data were then analyzed using the constant comparative method. This method or also known as coding [35] has been regarded to be the most popular type of qualitative data analysis [36]. The raw data were first transcribed and read through. Next, data were broken down into smaller meaningful parts and then labeled. Similar codes were grouped based on similarity. Finally, themes that represent the group were identified.

\section{RESULTS AND DISCUSSION}

The results of this study are separated into two sections: job stressors and coping strategy.

\section{A. Job Stressors}

There were three themes of job stressor that emerged from the analysis which were job characteristics, adaptation, and personal. The most common job stressor reported by participants of this study was job characteristics. The majority of participants described that the types of the task given daily were somewhat uncertain. Although, participants already set some expectations that hospitality jobs are typically variable. In other words, the tasks were not monotonous. This is particularly stressed by those who worked in a direct guest- contact atmosphere. Some participants also explained that they encounter different hotel guests who may ask for differen assistance every day. Furthermore, included in the task characteristic categories are lack skill, knowledge, and ability to speak English and/or other foreign languages. Indeed, to a certain degree, hospitality operations are challenging. First, it requires a high degree of emotional stability. Second, it is highly variable in terms of type, time of completion, and workload). In addition to the variation of tasks was the time of completion for each task was not necessarily fixed. That is, one task may take longer than others or one task can be completed in different ranges of time. Thus, it was hard for students to arrange their agenda, for example, as explained by one participant, if wanting to take a foreign language course after working hours. Third, it needs certain skills, knowledge, and language or communication ability.

The second category of the job stressor was personal. One female participant explained that she had an interpersonal issue that influenced her performance at work. Another female participant reported that she was sick and had to stay at home for several days. She was worried that it affected her overall performance evaluation. Furthermore, one male participant commented that he had a problem focusing at work. He described that he was somewhat forgetful to what was asked to do by his supervisor or senior co-worker.

In entering a real work situation, students may feel anxiety, uncertainty, insecurity [3], and lack of confidence despite having learned the skills on campus. As such, it can be expected that particularly during the first few days or weeks, students feel stressed or uncomfortable. This probation or adaptation period can be the starting point of deciding to continue the program or quit. In the worst case, students can decide to quit. Thus, another source of stress was an adaptation. It was apparent that this problem immediately occurred at the beginning of the program. The majority of the participants stressed that they needed at least two to three weeks to start feeling more comfortable. Only two male participants stated that they did not find any adaptation difficulties from the first day. These participants further explained that they felt familiar with the work due to their previous experience in the hotel operations training program. This means that familiarity with work situation enhance the level of confidence and thus, reduce the stress that is caused by adaptation process. In this regard, adaptation refers to task procedure, relationship with coworkers, and the culture of the organization.

\section{B. Coping Strategies}

In response to the stress at work, one may choose a coping strategy. Within the context of this research, participants were asked the way they respond to reduce or cope with the stressful working atmosphere. The analysis of this study showed that the majority of participants adopt direct action. That is, participants decided on an alternative to responding to the stressful working situation, for example, one female interns reported that she studied the restaurant menu at home for her to improve her product knowledge. Furthermore, the male respondent stated 
that he cannot remember the details of a task given chose to bring pen and paper all the time while he was on duty. $\mathrm{He}$ commented that being an easily distracted person, it is helpful to have note and pen at all times.

Furthermore, a few respondents adopted the internalizing strategy in coping with stressful situations at work. Respondents affirmed themselves that as time goes by, such a stressful adaptation period would diminish and finally go away. Lastly, only the female respondent who had personal issues adopted the avoidance strategy. The respondent reported that it would be better to avoid the unpleasant situation rather than living with it without a solution. She further explained that such a situation affected her performance and it may be fatal to the future continuity of her study. Nevertheless, with all types of stressful working situation, none of the respondents quitted from the on-the-job training program. All of them completed the program on time with the minimum category of achievement was satisfactory.

The findings of this study imply that campus, hotels/industry, and students are important actors of the success of the internship program [1]. It requires the effort of all three parties to work together and design a program that is beneficial for all. For the educational institution, it is imperative to consider inserting problem-solving subjects and including case studies in the teaching method. It is also essential to introduce the hotel working environment and the kinds of occurrence during on the job training program to students before the on-the-job training. Such an introduction helps the students to anticipate and to be more prepared. On the other side, hotels may take a more flexible approach in treating interns for example by allowing students to engage with guests and work more independently. This allows interns to grow and improve their competence which includes skill, knowledge, and attitude. Above all, the institution, hotel, and student need to periodically meet and discuss progress or problem during the on-the-job training and find solutions. With these actions, educators, employers, and students alike will be able to arrange more positive and enriching internships in the future. Such a life experiential program [37] needs to be planned, controlled, and assessed to provide familiarity with professional practice, but also to improve the value of the graduates in the labor market [38] and provide a unique win-win opportunity for all stakeholders. Furthermore, these two facets in the combination with campus and industry learning experiences will increase the ability to critically reflect on the hospitality and tourism business [39]. For the student, such experience can indeed be "a gateway to the real world" [40] that are beneficial for all the three parties [1].

\section{CONCLUSION}

On the job training is an important program for students [3], [2] particularly in vocational education. For hospitality students, this program allows them to experience the real operations of the hotel business. In other words, students are exposed to the daily hotel activities and directly engage in related tasks. Through this program, students enhance their skills, knowledge, and attitude and are more ready to pursue their future careers.

In line with its critical role in shaping students following the industrial requirement, the internship program needs to be assessed to ascertain its benefit for students. In particular, understanding how students cope with struggling situations in the industry requires attention due to students may not be ready. However, research within this area has considerably been limited. This study aimed at addressing such a gap and revealed that during the training program, the major problem was task characteristics in which students experience difficulty in job completion. Next, it was also found that direct action is the coping strategy mostly adopted by students in handling difficult and challenging work situations. This means that students are more inclined to alter the stressful situation or their relationship with the situations. Although exposed to stressful work situation, none of the research participants decided to quit the on the job training program. In other words, they all accomplished and completed the program as scheduled.

The results of this study imply that the hospitality educational institutions should provide students with teaching materials that focus on the practical component so that students are more familiar with the type or characteristic of the job. Moreover, the institutions need to include an introduction to hotel operational common cases in the curricula to prepare and improve students' readiness in dealing with such cases. On the other side, hotels should promote a more supportive environment and provide empowerment to help the student development in terms of skill, knowledge, and attitude as well as problem-solving ability. Besides, students, campus, and hotels need to periodically evaluate the progress of the intern students. Finally, the findings of this research have provided insights into the coping strategy of intern students in the hospitality context.

This research was exploratory in its nature. Thereby, the results of this study are not readily applicable to the wider and general population. Rather, it is specified within the context of this study. It may be represented in a similar research setting. The content analysis used in this study covered the placement reports of 23 students at one university's Hotel Operations Program. The findings apply to those students only and are not be generalized. However, the richness of the findings will allow the study to be used as a reference for other academic institutions in hospitality and tourism management, particularly in curriculum design and development.

The results of this study suggest an avenue for further investigations that in particular address the limitation of this study. A future study could employ a larger sample size from diverse cultural backgrounds, in order to obtain more generalized findings. Considering the importance of experiential learning in vocational education, examining factors affecting students' satisfaction toward on-the-job training program seems essential. Furthermore, future study may also implement a longitudinal study to look into the different phases 
(pre, during, and post-training program) encountered by students and the coping strategies adopted.

\section{REFERENCES}

[1] M. Yiu and R. Law, "A Review of Hospitality Internship: Different Perspectives of Students, Employers, and Educators," J. Teach. Travel Tour., vol. 12, no. 4, pp. 377-402, 2012

[2] W.-H. Ko, "Training, Satisfaction with Internship Programs, and Confidence about Future Careers among Hospitality Students: A Case Study of Universities in Taiwan," J. Teach. Travel Tour., vol. 7, no. 4, pp. 1-15, 2008

[3] V. Gamboa, M.P. Paixão, and S.N. de Jesus, "Internship Quality Predicts Career Exploration of High School Students," J. Vocat. Behav., vol. 83, no. 1, pp. 78-87, 2013.

[4] M.F. Toncar and B. V Cudmore, "The Overseas Internship Experience," J. Mark. Educ., vol. 22, no. 1, pp. 54-63, 2000.

[5] S.S. Cheng, C.K. Wu, H.H. Lai, and L.H. Sun, "Factors Affecting Taiwan Hospitality Students' Attitude on Internship,” in International Council of Hotel, Restaurant and Institutional Educators Annual Conference, Pennsylvania, 2004, pp. 38-42.

[6] H.-H. 'Sunny'Hu and C.-W. Cheng, "Job Stress, Coping Strategies, and Burnout among Hotel Industry Supervisors in Taiwan," Int. J. Hum. Resour. Manag., vol. 21, no. 8, pp. 1337-1350, 2010.

[7] S.-H. Tsaur and Y.-Y. Tang, "Job Stress and Well-Being of Female Employees in Hospitality: The Role of Regulatory Leisure Coping Styles," Int. J. Hosp. Manag., vol. 31, no. 4, pp. 1038-1044, 2012.

[8] F.F.T. Chiang, T.A. Birtch, and H.K. Kwan, "The Moderating Roles of Job Control and Work-Life Balance Practices on Employee Stress in the Hotel and Catering Industry," Int. J. Hosp. Manag., vol. 29, no. 1, pp. 25-32, 2010.

[9] J.W. O'neill and K. Davis, "Work Stress and Well-Being in the Hotel Industry,” Int. J. Hosp. Manag., vol. 30, no. 2, pp. 385-390, 2011.

[10] C.A. Young and D.L. Corsun, "What a Nuisance: Controlling for Negative Affectivity versus Personality in Hospitality Stress Research," Int. J. Hosp. Manag., vol. 28, no. 2, pp. 280-288, 2009.

[11] O.M. Karatepe, E. Babakus, and U. Yavas, "Affectivity and Organizational Politics as Antecedents of Burnout among Frontline Hotel Employees,” Int. J. Hosp. Manag., vol. 31, no. 1, pp. 66-75, 2012.

[12] J.J. Lee and C. Ok, "Reducing Burnout and Enhancing Job Satisfaction: Critical Role of Hotel Employees' Emotional Intelligence and Emotional Labor,” Int. J. Hosp. Manag., vol. 31, no. 4, pp. 1101-1112, 2012.

[13] Y. Liang, "The Relationships among Work Values, Burnout, and Organizational Citizenship Behaviors,' Int. J. Contemp. Hosp. Manag., 2012

[14] Y.-C. Hsieh and P.D. Eggers, "Coping Strategies Used by Lodging Managers to Balance Work and Personal Lives: An Exploratory Study," Int. J. Hosp. Tour. Adm., vol. 11, no. 1, pp. 39-58, 2010.

[15] H.J. Kim and J. Agrusa, "Hospitality Service Employees' Coping Styles: The Role of Emotional Intelligence, Two Basic Personality Traits, and Socio-Demographic Factors,” Int. J. Hosp. Manag., vol. 30, no. 3, pp. 588-598, 2011.

[16] M.J. Kim and S.Y. Han, "Relationship between Emotional Labor Consequences and Employees' Coping Strategy," Asia Pacific J. Tour. Res., vol. 14, no. 3, pp. 225-239, 2009.

[17] Y. Strizhakova, Y. Tsarenko, and J.A. Ruth, "'I'm Mad and I Can't Get That Service Failure off My Mind' Coping and Rumination as Mediators of Anger Effects on Customer Intentions," J. Serv. Res., vol. 15, no. 4 , pp. 414-429, 2012.
[18] Y.-C. Wang, R. Cai, C.-E. Yang, and H. Qu, "Coping Strategy in Hospitality Internships: A Mixed Method Approach," J. Hosp. Tour. Educ., vol. 27, no. 1, pp. 10-19, 2015.

[19] T. Hyland, "Vocationalism, Work and the Future of Higher Education." Taylor \& Francis, 2001

[20] C. Le Maistre and A. Paré, "Learning in Two Communities: The Challenge for Universities and Workplaces," J. Work. Learn., 2004.

[21] T. Fox, “A Sense of Place," Cater. Hotelk., vol. 189, no. 4160, pp. 3031, 2001.

[22] E.J. Randall and D.J. Good, "An Analysis of Marketing Internship Programs,” J. Educ. Bus., vol. 66, no. 4, pp. 228-231, 1991.

[23] C. Ross, B. Beggs, and S. Young, Mastering the job search process in recreation and leisure services. Jones \& Bartlett Learning, 2011

[24] L.S. Gross, The internship experience. Belmont, CA: Wadsworth, 1981

[25] T.S.M. Tse, "What Do Hospitality Students Find Important about Internships?," J. Teach. Travel Tour., vol. 10, no. 3, pp. 251-264, 2010.

[26] L. Dragoni, I. Oh, P. Vankatwyk, and P.E. Tesluk, "Developing Executive Leaders: The Relative Contribution of Cognitive Ability, Personality, and the Accumulation of Work Experience in Predicting Strategic Thinking Competency," Pers. Psychol., vol. 64, no. 4, pp. 829864, 2011.

[27] M. Shinn, M. Rosario, H. Mørch, and D.E. Chestnut, "Coping with Job Stress and Burnout in the Human Services.," J. Pers. Soc. Psychol., vol. 46, no. 4, p. 864, 1984.

[28] G.D. Sideridis, "Coping Is Not an 'Either' or': The Interaction of Coping Strategies in Regulating Affect, Arousal and Performance," Stress Heal. J. Int. Soc. Investig. Stress, vol. 22, no. 5, pp. 315-327, 2006

[29] S. Lee and W. Lee, "Coping with Job Stress in Industries: A Cognitive Approach,” Hum. Factors Ergon. Manuf. Serv. Ind., vol. 11, no. 3, pp. 255-268, 2001

[30] R.S. Lazarus and S. Folkman, Stress, appraisal, and coping. Springer publishing company, 1984.

[31] A. Dadkhah, "Stress Managment and Health Promotion," Iran. Rehabil. J., vol. 2, no. 1, pp. 26-33, 2004

[32] J.C. Latack, "Career Transitions within Organizations: An Exploratory Study of Work, Nonwork, and Coping Strategies," Organ. Behav. Hum. Perform., vol. 34, no. 3, pp. 296-322, 1984.

[33] M. Stevens and D.J. Higgins, "The Influence of Risk and Protective Factors on Burnout Experienced by Those Who Work with Maltreated Children," Child Abus. Rev. J. Br. Assoc. Study Prev. Child Abus. Negl., vol. 11, no. 5, pp. 313-331, 2002.

[34] R. Puhakka, S.P. Cottrell, and P. Siikamäki, "Sustainability Perspectives on Oulanka National Park, Finland: Mixed Methods in Tourism Research,”J. Sustain. Tour., vol. 22, no. 3, pp. 480-505, 2014.

[35] M.B. Miles and A.M. Huberman, Qualitative data analysis: An expanded sourcebook. sage, 1994

[36] N.L. Leech and A.J. Onwuegbuzie, "An Array of Qualitative Data Analysis Tools: A Call for Data Analysis Triangulation.," Sch. Psychol Q., vol. 22, no. 4, p. 557, 2007.

[37] A. Walmsley, R. Thomas, and S. Jameson, "Surprise and Sense Making. Undergraduate Placement Experiences in SMEs," Educ. Train., 2006.

[38] G.D. Busby and P. Gibson, "Tourism and Hospitality Internship Experiences Overseas: A British Perspective," J. Hosp. Leis. Sport. Tour. Educ., vol. 9, no. 1, p. 4, 2010

[39] J. Tribe, "Research Paradigms and the Tourism Curriculum," J. Travel Res., vol. 39, no. 4, pp. 442-448, 2001.

[40] A.B. Collins, "Gateway to the Real World, Industrial Training: Dilemmas and Problems," Tour. Manag., vol. 23, no. 1, pp. 93-96, 2002 